\title{
THE FEASIBILITY OF SMALL GRAINS AS AN ADOPTIVE STRATEGY TO CLIMATE CHANGE
}

\author{
Svodziwa Mathew, Lecturer \\ Bulawayo Polytechnic, Bulawayo, Zimbabwe \\ E-mail: mathewsvodziwa@gmail.com
}

\begin{abstract}
The paper examines the feasibility of small grains as an adoptive strategy to climate change in Siansengwe, Binga District. Climate change and variability have resulted in a shift in the rainfall patterns in many parts of the world. Successive droughts in Zimbabwe compounded by other economic shocks in recent years have resulted in decreased maize productivity amongst the communal farmers most of whom reside in regions IV and $\mathrm{V}$ which are considered semi-arid. This has resulted in the prevalence of food insecurity particularly to these semi-arid regions as unreliable rainfall has undermined subsistence farming. The environment in Siansengwe, Binga is no longer conducive for maize production due to the unfavorable weather patterns. This has given rise to the need to find alternative food crops, which may be suitable for these areas. According to the research, significant changes have been experienced in the size, structure and composition of the five natural regions. This survey notes that priorities for developing the small grains food system must be derived from a sense of the structure of supply and demand for these grains. They must also reflect an understanding of how grain policies, infrastructure, and technology affect incentives for production and consumption. Strategies designed to improve the performance of the small grains food system should be defined in terms of specific changes in the various components of this enabling environment. The study that there is need to incorporate small grains in semi-arid areas. The study shows how small grains have been adopted in Siansengwe and the impact that small grains have on food security as they can enhance food accessibility, utilization, stability and availability. Small grains production can be the way forward in the provision of food security in drought prone areas like Siansengwe, Binga.
\end{abstract}

\section{KEY WORDS}

Feasibility, Small Grains, Adoptive, Climate Change.

The increase in greenhouse gas emissions is raising the earth's temperature and the consequences include varying precipitation, extreme weather events (droughts and floods) and shifting of seasons. Bang (2003:90) notes that the rapid pace at which climate change is taking place, combined with the increase in global population and slow income growth, threatens food security globally. Agriculture has proved to be extremely vulnerable to climate change as seen by the drastic decline in food production over the past two decades. High temperatures that are being experienced in most parts of the globe will eventually reduce yields of desirable crops while encouraging weed and pest proliferation. The changes in precipitation patterns will significantly increase the likelihood of crop failures and production declines (Juana, 2012: 34). Although scientific evidence proves that there will be gains in some crops in some regions of the world where the climate has shifted towards favorable conditions, the overall impacts of climate change on agriculture are expected to be negative, threatening global food security, (Mallet,2001:34).

The complex challenge of improving food security involves an interdependent and interconnected set of issues, including agriculture, energy, the environment, government policy and trade (Dercon, 2002). In a country where agriculture is the dominant source of livelihood, responding to climate change should be a priority. There have been a myriad of solutions suggested by scientists and development practitioners which have not yielded much success. However, one way that can promote food security is small grain production. Small grain production has become widespread in dry areas with promise of enhancing food security if planted on a larger scale (FAO,2010). 
The study argues that food security and agricultural production are interconnected and the best way of tackling this is to focus on adaptation means and the correct crops to grow. Small grains like sorghum and millet provides the breakthrough to Africa in this $21^{\text {st }}$ century of climate change and drought. They have been noted by experts to be better performers in drought-prone areas and are considered to have better nutritional value than maize, which is viewed as an unsuitable crop in these agricultural regions, (Barret, 2005). This has led to their adoption as staple food grains in many semi-arid and tropic areas of the world, particularly in Sub-Saharan Africa because of their good adaptation to hard environments and their good yield of production (Wilhite, 2005). Maunder (2006) expands on these findings by describing sorghum and millet as generally the most drought-tolerant cereal grain crops that require little input during growth and with increasing world populations and decreasing water supplies, represent important crops for future human use.

Limited rainfall, dry spells and drought have significantly reduced agricultural yields especially in semi-arid regions in rural areas leading to food insecurity. The semi-arid areas are characterized by unpredictable weather, limited and erratic rainfall and nutrient-poor soils and suffer from a host of other agricultural constraints (Mallet, 2001). In addition, Riches (1997:23) highlighted that there is an urgent need to focus on improving crops relevant to the smallholder farmers and poor consumers in the semi-arid areas of the developing countries. As highlighted earlier, this can be achieved through the development and use of crops that are adaptable to these environments. Small grain production could be the response needed to address the effects of food security in Binga. These crops could be the panacea to the problems of food insecurity posed by drought. Research has shown that in these regions small grains have the potential of stabilizing household food security (Amnesty International, 2004).

Significant improvements are still needed in the productivity of small grains, but priority must also be placed on the establishment of a postharvest market system to employ these technologies efficiently. Broadly defined strategies are needed to ensure that sorghum and millet will become more competitive on both rural and industrial markets and, more importantly, to increase the contribution of small grains to the resolution of persisting food deficits, (World Bank, 2008:90).

\section{LITERATURE REVIEW}

Agriculture plays an important role in the development of the Zimbabwean economy through its impact on the overall economic growth, households' income generation and food security (Scoones, 1998:78). According to Juana (2005), it offers income and employment to about $70 \%$ of the population, $60 \%$ of the raw materials required by the industrial sector and is the largest export earning sector contributing about $45 \%$ of total exports in most years. As such, the sector creates employment opportunities for about $25 \%$ of the total work force in formal employment and contributes an estimated $17 \%$ of Gross Domestic Product (GDP) (Ndlovu, 2011). In comparison other sectors such as mining, manufacturing, electricity, construction and services contribute five percent, twenty seven percent, three percent, three percent and 47 percent respectively to the GDP (Juana, 2005).

However the prevalence of drought has undermined agricultural production in Zimbabwe. Juana (2005) indicate a situation where in Zimbabwe, between 1960 and 1992, average annual rainfall was $662.3 \mathrm{~mm}$ and maize yields fluctuated widely at that time, ranging from 2.4 tonnes per hectare (2.4 t/ha) in 1986 to as low as $0.4 \mathrm{t} / \mathrm{ha}$ in 1992. Dube (2008) alleges that in 2007 , only 45 per cent of national cereal requirements were produced in the country leaving a deficit of over 610,000 metric tonnes to be covered by imports and cattle population declined from approximately 6.1 million in 2000 to 5 million in 2011, while dairy production dropped from over 100,000 cows in 2000 to approximately 22,000 cows in 2010. Dercon (2002:78) notes that in this regard rural livelihoods are negatively affected as there is a higher dependence on agriculture.

Rukuni (1994:56) notes that rising temperatures and increasing rainfall variability, notably drought, are also expected to exacerbate declining agricultural outputs, further 
compromising economic growth and stability, employment levels, food insecurity, demand for other goods, and poverty reduction. FAO (2000) propounds that climate change is expected to lead to the expansion of marginal lands, which is already beginning to occur in Zimbabwe. It is alleged that if changing climatic conditions continue to expand, traditional agricultural systems will become increasingly unsustainable to such an extent that even diversified livelihood systems with a livestock component are expected to become more vulnerable (Bang, 2003).

Rohrbach (2007) report that Zimbabwe's water supply is deteriorating as a result of persistent drought that severely strain surface and ground water systems. Surface water from mostly rivers and dams is the major source of water in Zimbabwe accounting for 90 per cent of supply while the potential to use ground water has not yet been realized mainly due to the unaffordability of the required technology (Ndlovu, 2011). They allege that surface water is prone to high loses due to evaporation caused by high temperatures, where for example, in 2007, evaporation led to extremely low water levels in most of Zimbabwe's dams, causing many to be decommissioned and the situation becomes worse with climate change where evaporation is predicted to increase by between 4-25 per cent in the river basins and runoff is also projected to decline by up to 40 per cent, with the Zambezi Basin worst affected (World Bank, 2008).

Annual rainfall levels based on the 1961-90 average are also projected to decline between 5-20 per cent by 2080 in all of the country's major river basins and these projections will worsen the existing deficiency of water resources, particularly in the agro ecological zones IV and V (Dube, 2008:89). In this regard this research proposes that responses like small grain production should be promoted as the way forward. Small grains are resistant to drought and diseases as well. In addition, the research will give an enhanced insight through the qualitative approach. Most researches done on drought and food security have tended to be quantitative. A qualitative approach was used as a way of confirmation and as a way of bringing new results in the field of drought and small grain production.

\section{POLICY ON SMALL GRAINS PRODUCTION IN ZIMBABWE}

In spite of the past measures to stimulate rural food production and incomes, food insecurity remains highly prevalent in the low rainfall communal areas of Zimbabwe, (Rohrbach, 2007). Evidence suggests that past increases in food grain production and marketing has been both concentrated in high rainfall regions and within regions, most of the marketed surplus was produced by a small proportion of the households. Maunder (2006) notes that there is no clear cut policy of promoting small grains production among the small holder farmers in Zimbabwe's semi-arid areas where they are thought to have a comparative advantage over maize particularly regarding their research. The same views were upheld before by Riches (1997) that production of small grains has been on the decline in Zimbabwe due to policies that favor production of maize.

However Barret (2005) is of a different opinion that for decades policy makers have encouraged the production of small grains in Zimbabwe. This was in the belief that they will reduce food shortages in communal areas, which lies in natural regions four and five. Furthermore Barret (2005) adds that policy makers thought that these crops would subsequently out compete maize in these semi-arid regions. Nevertheless, it has been shown that maize, particularly the shortest season varieties, has out yielded small grains in these regions, (Dube, 2008). Maunder (2006) attributes this higher yield to more research efforts being channeled into maize than to small grains.

\section{MARKET DEVELOPMENT FOR SMALL GRAINS}

In Zimbabwe, the need for cash by rural farming families has been such that crops that are suitable for agro-ecological regions have often been overridden for maize production,( Rukuni, 1994:43). In these regions, maize has a ready market and it can be easily traded to meet other financial obligations. Governments need to come up with policies that favor the 
development of competitive intra-rural markets if small holder farmers are to be encouraged to grow small grains. FAO (2000) argues that development of small grains will act as a great incentive for rural farmers in these semi-arid regions to grow these crops. This is because they will now be growing them for both subsistence household food security as well as cash crops to meet other financial demands, (Wilhete, 1991:21).

Zimbabwe's formal market handle less than $10 \%$ of the total small grains. In addition, FAO (2010) noted that most of the small grains produced in Zimbabwe is consumed by the producing household or sold in the informal markets, mainly for traditional beer brewing. However, in Zimbabwe the price of maize in the informal markets is cheaper than that of sorghum and millet. Hence in terms of market potential there is good reason to expand production of small grains in Zimbabwe's rural areas in view of the price differences.

\section{STUDY AREA AND POPULATION}

Sinansengwe ward is found in Binga District, which lies in the Northern side of Matabeleland Northern Region where the Zambezi River (Lake Kariba) marks the boundary between Zambia and Zimbabwe. The sparsely populated ward ( 5566 people according to 2012 population draft census report with 870 households) is surrounded by Chizarira National Park (1640 sq km) to the east and Chete National Park (1341sq km) to the west and towards the Zambezi river. The figures mark a remarkable increase in population by $29 \%$, since the 2012 census pegged it at 3949 and distributed among the five distinct villages of Chitete, Mucheni, Makondo, Malindi, and Siakabinga Chitete. The National Park prevents the Sinansengwe population from accessing water, fish and other resources from the mighty Zambezi River (Juana, 2012).

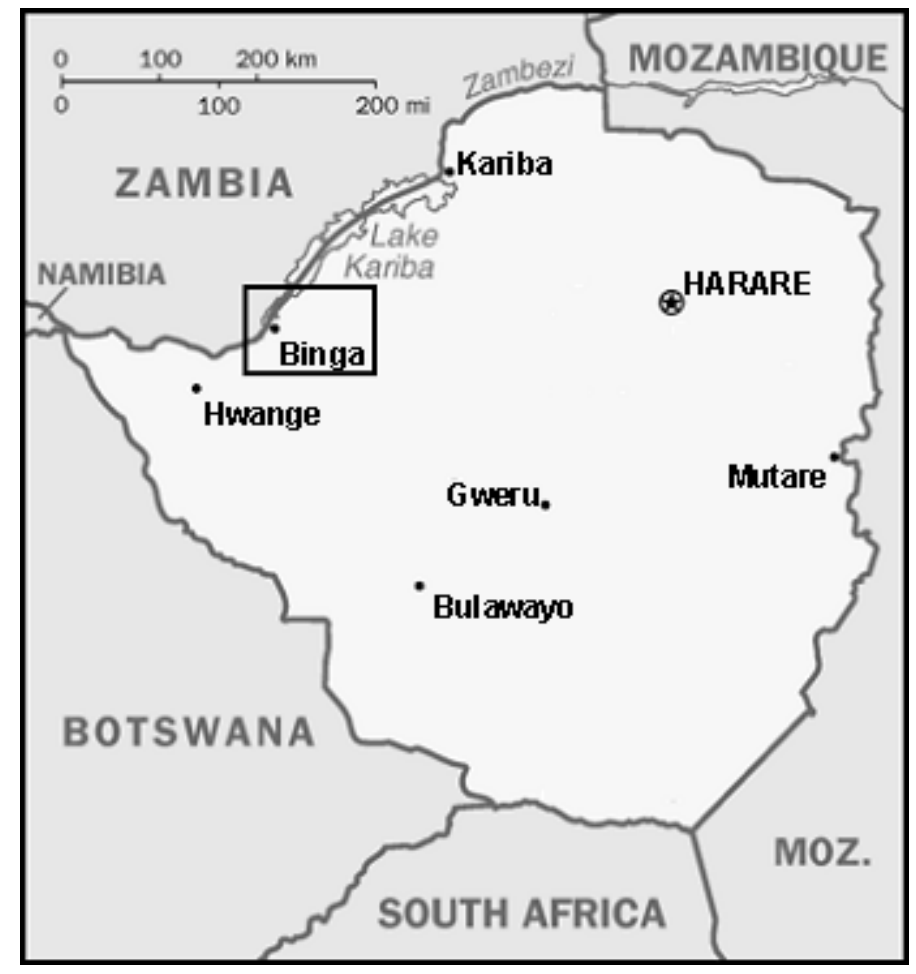

Sinansengwe ward suffers from a great deal of food deficit attributed to low rainfall, compounded by limited arable land and patch arable soils according to Mwaramba and Associates (2001). The ward has two main seasons - the dry warm winters and the hot wet summers. The temperatures are high and rainfall quite unreliable.

The adoption of Binga district semi-arid areas is not by accident but has been motivated by the fact that for the past two decades, the afore mentioned areas, among others in Zimbabwe and beyond, have witnessed pronounced increases in temperature, 
recurrent droughts and unpredictable rainfall patterns, yet people mainly depend on rain-fed agriculture and natural resources for their livelihoods. Receiving low rainfall and experiencing high temperatures, place this area in one of the most vulnerable regions to climate change in Zimbabwe (Rukuni, 1994:23).

\section{RESEARCH METHODOLOGY}

The research relied on participatory rural appraisal technique to gather primary data, where focus group discussions, face-to-face interviews and questionnaires were administered. There were identified through random sampling to ensure that every member of the ward had an equal chance of being chosen and for the research to be reflective of the community views. The random sampling technique is simple to use and easy to apply when small populations are involved, though it is cumbersome for large populations. Each household was numbered and this was used to select the required sample.

Focus group discussions were also applied in gathering data at ward level where community members with different portfolios were involved. They included traditional chiefs, kraal heads and communal farmers. Face to face interviews were held with development agencies of both government and nongovernmental organizations concerned with small grains. Key respondents included 6 from AREX office, 4 from Community Development Department in Women Affairs, and 15 farmers. These respondents were chosen specifically because, for instance the AREX officers are directly involved with disseminating information about small grains to the local farmers in Binga. The 15 farmers involved were largely the concern of the study as they were the ones producing the small grains or choosing not to produce and in so doing their views were the central concern. Face to face interviews offered a great advantage of probing with the respondents on the subject. They offered the researcher a distinct advantage of immediate feedback as the respondents' emotions were shown clearly on their faces. Also non-verbal cues gave the researcher messages which helped in understanding the verbal responses, which will be changing or even, in extreme cases, reversing or contradicting its meaning. Notably one of the advantages of these types of interviews is the fact that the most respondents had a hard time in turning down the interviewer. They also provided instant responses which helped the researcher to make quick decisions.

Questionnaires were administered especially to those not easily reachable during normal working hours as that saved time and ensured their views were taken into account during the research. Secondary data were archives, provincial and district offices, rural district council, survey maps and reports from previous studies.

Ethical considerations. According to Carney (1999), professional codes are essential to protect participants in social research from harm, while ensuring the right of privacy adhering to the action of informed consent and avoiding deception. Ethical dilemmas are likely to emerge during collection of data and publication of research findings. This research adhered to codes of strict ethics during data collection. A sense of expertise was carried out giving the respondents respect. In addition the researcher sought permission from the responsible local authorities first before undertaking the research. Participants were assured that the information they provided would be confidential and used solely for stated purpose of the study.

\section{ADAPTABILITY OF SMALL GRAINS TO CLIMATE CHANGE}

Small grains have been noted as staple food grains in many semi-arid and tropical areas of the world particularly in Sub-Saharan Africa because of their good adaptation to harsh environments and their good yields of production. Bang (2003:45) notes that small grains are generally the most drought-tolerant cereal grain crops that require little input during growth and with increasing world populations and decreasing water supplies, represent important crops for future human use. 
Small grains have got the potential to contribute towards the food security of many of the world's poorest and most food insecure agro-ecological zones. This can be achieved through increasing production and productivity of these crops in such agro-ecological zones. These conclusions concur with those of Bang (2003) that small grains have the potential to improve household security in semi-arid regions because of their adaptability to such environments. Despite this, research on these crops has been lagging behind in Africa because they suffer something of an image problem and there often tend to be an preference for maize as the premier crop.

Small grains like sorghum and finger millet have proved to have a high percentage of availability. For instance, finger millet when properly dried can be stored up to a period of five years. In such a case this promotes its availability and thus strengthen issues to do with food security. The strength of small grains when it comes to food availability is shown by the realization that small grains like millets can make flour and from the flour only a small amount is required to make bread which ensures food availability for a long period. In this regard, Dube (2008) pointed out some advantages of small grains like sorghum and millets over maize as: a smaller amount of flour is needed to cook the main meal compared to maize; a meal cooked from the small grains satisfies hunger for a longer period and gives more energy (which is especially important for persons who do heavy manual labor like farmers).

When maize is planted in dry areas, it is highly affected by temperature and will result in very limited yields. Availability of maize is also limited as it can be stored for over 2 years as insects are more likely to feed on it. This renders the fact that small grain production should be the way forward in drought prone areas. The majority of households in Siansengwe especially those who are regarded as poor are likely to have their maize stock run out quick within less than a year. This could be attributed to the fact that they could have failed to apply fertilizer due to lack of finances. This is however different with small grains as they do not highly require fertilizer.

According to an officer from Agritex:

"What I have realised is that in many respects maize requires several inputs for a bumper harvest to be realised. Fertiliser is the highest requirement but it again depends on water availability. In Siansengwe having fertiliser and applying it on maize might actually worsen the situation. Maize crops dry up if fertilizer is applied where there is limited rainfall like in Siansengwe."

The researcher received several responses similar to this which showed that Binga is no longer suitable as a maize growing area. A comparison on of maize yields and millet in line with one's respondents sentiments showed that producing millet should highly be taken into consideration and this will mean food availability for many. From the above it can be stipulated that small grains had the positive impact of providing food availability to those farmers who produced it compared to other farmers who concentrated on maize.

\section{CONSUMPTION}

In Sinansengwe emphasis on small grains is being done as the surest way of promoting food accessibility. This has produced positive results in this area as accessibility to finger millet has since increased specifically to those farmers who have adopted this production. To those households who have planted small grain production, food accessibility is now within their reach. It has meant that they can no longer have to go with no food compares to other previous years.

Food accessibility can be heightened by both finger millet sorghum. According to Ndlovu (2011), these drought resistant crops have become extremely important to the local community given the fact that they act as both food and cash crops which enables the smallholder farmers to adapt to climate change and variability and attain sustainable livelihoods. Small grains have been used in beer brewing. Locals produce beer which is later sold and called 'Ndari' or "7 days". It is common in the area and most people just farm small grains for the main purpose of making this beer. This traditional beer is providing as an alternative source of income for many people who brew it commercially. $70 \%$ of the 
households who grow small grains have been brewing beer from these crops and selling the beer increasing their access to cash. The study analyzed the economics of using sorghum and millet in processed form as traditional beer. Results show that traditional beer production adds value to small grains with a potential to realizing a good gross profit. The study concludes that traditional beer is therefore an important source of cash income in the semiarid smallholder sector.

The poor and middle groups and some of the better-off indicate that beer brewing is a very popular way of paying such costs as school fees as the profits realized are very high. The money is also used to buy other food commodities making food to be accessible at most times. In some wards such as Mapirimira village, beer brewing clubs were formed in an effort to control over supply of the commodity in order to maximize demand and better returns. The club members not only contribute money that is given to one member at a time so that they manage to buy all the ingredients required for beer brewing but also give each other chances for brewing the beer so that there is no competition for customers. The club members have three to four opportunities of brewing and selling the beer over the year. The income raised could be used to purchase supplementary food during drought periods. Small grains have been commercialized to a smaller extent and some farmers are selling their produce to GMB who later sell this to Delta a brewing company that brews the famous 'chibuku'. Some of this money is also being used to purchase the next season's seeds. However other farmer's interviewed pointed out that sometimes GMB refuses to buy their grains pointing that they need to produce more if they want to sell making the grains to be a challenge to sell on a national level (Dube, 2008).

This beer has been brewed since the pre-colonial times with the sole purpose of performing ritual ceremonies and in some cases this is still being practiced in the area. The most popular ceremony is 'nhimbe' whereby the community collaborates collectively in their agricultural activities and then later on drinks this traditional beer. This has been of great help in the area especially to those vulnerable homesteads with individuals with HIV/AIDS, orphans and widows. This kind of ceremonies have managed to assist the vulnerable people to improve food accessibility as they can now be able to have their farms cultivated and also expect yields and improve their access to food. Other uses of the beer in the area have been for what is termed 'kurova guva' a death ritual and in the Nyama area one household actually stated that they produce this beer every year in order to carry out traditional ceremonies like 'mukwerere' a rainmaking ceremony. Household income may also be enhanced by sale of finger millet and income generated through trade as well as production. According to one respondent she argued that, they plant sorghum to sell or trade with other households.

\section{CHALLENGES IN THE PRODUCTION OF SMALL GRAINS}

FAO (2000) notes that production of small grains continues to suffer due to the fact that it offers low yields. FAO (2010) further alludes that low yields of small grains have acted as a major obstacles and challenges for communal farmers in Zimbabwe's semi-arid regions to expand and adopt production of small grains one large scale compared to maize. This lower productivity causes small grains to be very unattractive to farmers though there is climate change.

\section{DEPREDATIONS OF THE QUELEA BIRDS ON SMALL GRAINS}

Communal farmers also noted that as a major challenge they faced the depredations of the quelea birds on small grains. Following this further, research has shown that rising labor costs in small grain production has affected most farm operations, from land preparations, weeding, bird scaring to harvesting and grain processing, (Barret, 2005:57). In addition, the ease with which maize can be processed compared to the traditional staples of small grains is the other main reason why maize became widely accepted even in Zimbabwe's semi-arid regions during the Green revolution. 
Wilhete (2000) notes lack of processing technologies as yet another factor that has hindered the development of alternative formal markets of small grains. By using traditional processing technologies, small grains take longer to process than maize especially during harvesting. This factor has reduced its demand by even the poorest of poor communal households.

Communal people also noted that even though climate change has devastating impacts. This is because small grains do not yield much crop residue, which plays a very important role to communal farmers in terms of animal feed and crop manure. Similar observations were noted by Wihete ( 2005) that livestock depend upon crop residents for survival during winter mainly from maize stores.

\section{PROFITABILITY}

Another very important factor, which has been acting as a production constraints towards small grains is changing food preferences. FAO (2010) notes that as incomes rise, consumers tend to purchase wheat, rice and in some cases maize, rather than small grains. As a result, communal farmers tend to view small grains as having lower returns than other enterprises. Real producer prices for small grains dropped considerably, since the trade liberalization program, compared to that of cash crops and maize. This also has acted as a major reason why communal farmers have shunned small grains production in favor of maize.

\section{LACK OF GOVERNMENT SUPPORT}

Rukuni (1994) argues that lack of government support in Zimbabwe for production, processing and use of crops that are tolerant to drought has resulted in people in the drier areas changing their tastes from small grains to maize. However for small grains to view with maize in the limited resources of the communal farmers, there is need to outperform maize in terms of the yields.

This as noted Arex Officers entails massive investment by government and the private sector in the development of hybrid small grains varieties that have higher yields and better taste than maize. Researchers are too isolated from farmers. Most research is initiated on research stations; not enough takes place on farms. More emphasis must be placed on diagnosing problems on-farm by multidisciplinary teams and analyzing indigenous technologies and current farmer practices.

\section{ECONOMIC GROWTH}

Taylor et al (2006) notes that commercial processing of small grains into value added products in developing countries has the potential to stimulate economic development in Zimbabwe. Therefore, policies that support increased production of small grains should be viewed in a holistic approach regarding contributions they can make to the macro-economy and not only as a means of increasing food security to those in the semi-arid areas.

In Zimbabwe, it has been deduced that the industrial and commercial use of small grains is generally limited. That being the case, Rohrbach 2007) mentions that small grains will increase industrial use which will have ripple effects besides just improving rural food security. These include but not limited to reducing the need for drought relief, lowering the level of subsidies underlying grain markets and at least in the short run, stemming migration from rural to urban areas.

Small farmers in the semi-arid areas are starved of appropriate pre- and postharvest technologies to suit their farming systems and circumstances. The tradition of selection and management for maximum yield of a single crop does not meet the need to maximize returns from a multi commodity farm system, (Carney,1999). 


\section{PROCESSING SMALL GRAINS IN RURAL AREAS}

ENDA is executing a project for the wider dissemination of small grain mills, including dehullers for use on sorghum and pearl millet. One reason for a shift from small grains to maize is the ease of processing of maize. Eliminating the processing "bottle-neck" for small grains may increase their production and use. The strategy is to bring the processing equipment as close to the producer as possible to stimulate the rural economy.

The Rural Industries Innovation Centre (RIIC) in Botswana and ENDA in Zimbabwe have demonstrated that rural processing of small grains can be achieved. There must be effective demand for processing, sites must be carefully selected, the scale of technology must be appropriate to the needs of the communities, credit must be generated, maintenance systems must be established, and entrepreneurship must be stimulated and developed in potential mill owners. A sustainable system of delivery of the machinery and training in its use must be established. In Siansengwe, the respondents noted that there is no technology to process the sorghum and millet.

\section{SMALL GRAINS AS INDUSTRIAL RAW MATERIALS}

Unreliable quality of small grains has discouraged and frustrated commercial processors who attempt to use them. In addition, work is needed on the forward and backward linkages that ensure a continuous and consistent supply of grain for From a utilization perspective, small grains are not viewed merely in the context of competitive advantage" over maize; they are an additional and underused resource in the cereal subsector of the food supply. Care must be taken not to differentiate too sharply between urban and rural demands and markets. In terms of uses and products, similar demands exist in both target areas, for example, porridge meat bread, and opaque beer. The main differences lie in level of technology and scale of operations. Conversion of the grains to usable products can be simple or complex, small scale or industrial scale (Bang,2003).

The aim in upgrading and improving the small grains sector is to accelerate transition of the current peasant-grown, subsistence crop to a commercial crop and to bring these grains into the mainstream of cereal use and trade, (Wilhite, 2005:34). Efforts to ensure good genetic quality must be matched by good postharvest practices to achieve consistent and high quality for market. Grades and standards for food use of small grains are lacking in most SADC countries or are inappropriate, because they were developed mainly for feed grains and brewing sorghum, (Mallet,2011:67).

Industrial processors, such as millers or brewers, enforce specific and stringent quality standards for evaluating their raw materials processing. Current research work of the Food Technology Unit comprises: identification of potential and current products and technologies and opportunities for replacing imported grain or making up deficits with local grains in existing and new food products; development of appropriate food products; bulk grain production for a pilot plant and in-plant trials; product and process optimization in in-plant trials with processors; technology transfer and adoption leading to eventual full-scale industrial processing, (FAO,2010).

\section{ACCEPTABILITY}

Sorghum and millet are important traditional cereal crops in southern Africa for food security and are largely grown by smallholder farmers. In long-distance food chains, storage, processing, distribution and marketing processes contain in-built mechanisms have protected the global food system from instability in recent times. However, if projected increases in weather variability materialize, they are likely to lead to increases in the frequency and magnitude of food emergencies for which neither the global food system nor affected local food systems are adequately prepared. Furthermore stability captures the consistence and reliability of food availability and access. It means that the house should not risk losing access to food as a consequence of sudden shocks. 
According to one respondent from the Sinansengwe,

"...when we produce small grains we are always sure of accessibility and that when problems arise millet can be stored for a long period as compared to maize."

Droughts in the area have affected food stability in most of the rural households as low production yields have left people with no food and depending on food aid. This is an example of how food insecure the people are as there are easily affected by drought and left with no food. The main reason for this is the production of maize a crop that is easily affected by drought and cannot thrive and produce any meaning yields in the hot areas of Sinansengwe. However, the crops face stiff competition from alternative crops such as maize in the production system. This is one factor that has contributed to food instability in Sinansengwe. However the planting of sorghum will promote stability in households as these crops are not affected by harsh conditions that prevail in Sinansengwe. These grains have managed to stabilize food in those households that have shifted from maize to small grains. These households have managed to quickly recover from droughts as these grains can be stored for many years without being affected by pests and diseases. Therefore as the area witnesses' prolonged dry spells, it is important for farmers to undertake the farming of small grains seriously, unless where circumstances avail like irrigation facilities.

\section{IGNORANCE BY THE COMMUNITY}

It was realized by the research that people tend to be largely ignorant about small grain production. Many farmers in Binga ignored the calls to adopt small grain production and in many instances continued to produce maize despite the realization that they are likely to get very low yields due to drought. This is mainly so because they prefer and will continue to prefer maize production. Most farmers have failed to acknowledge the significance of small grain production as they are driven by the taste of maize. The fact that small grain production is only being promoted in semi-arid areas while other areas in town are likely to continue farming maize make them ignore their condition and proceed with maize cultivation.

The ignorance by farmers on the production of small grains has led to crops like finger millet to be considered as neglected crops both at national as well as international levels. The production of this crops instead of rising have continued to decline rapidly, a fact that is raising questions considering its enormous benefits particularly to the poor in drought-prone areas. Furthermore most farmers have the problem of not prioritizing small grains as some of them grow these crops in their waste part of arable land whilst others ignore the effective time of planting. This really has a negative effect on their production.In addition the farming of small grains like finger millet require knowledge especially during weeding time as it tends to have weeds that look exactly like the plant. To the unpracticed eyes it is difficult to distinguish and this may result in pulling out the finger millet leaving out the weed. Therefore there is a need for the more education lessons for these crops among the rural households especially the young generation, (Amnesty International, 2004:89).

The above are the challenges that have been realised in small grain production. A combination of problems such as lack of certified small grain seed in the market, tastes and preferences as a contributory factor that is derailing the production of small grain, (Dube, 2008:9). For instance thick porridge prepared from white maize is more preferred than small grains. Some of the general factors include the fact that production of small grains is affected by poor prioritization of resources. Most farmers do not allocate more inputs to small grains. Some grow small grains in their worst part of cropping land and others do not prioritize time of planting and fertilizer management. This really has a negative effect on their production. Most farmers are not even aware of fertiliser use in small grains during the look and learn visits. In addition most do not know about weed management in small grains. Many assume that once the crop is planted it grows up to harvesting without weed control. In such a case there is need by the government and the NGOs involved to promote fertilizer use in small grains. Currently, few farmers use fertilizers on small grains. Future demonstration plots must have such message to the farmer. In addition, number of farmers for finger millet 
demonstration plots must increase to a village or even a ward if seed is availed to encourage farmers to grow the crop, (Mallet, 2001:12).

\section{LACK OF MARKETS}

One major disadvantage of small grains cited by respondents is the limited marketing opportunities. Although a lot of publishing and research has been done for these crops there is still lack of markets. The majority of respondents complained about the absence of a ready market for small grains. If farmers had a reliable buyer then they are able to maximize their total gross production. In Binga farmers could not rely on GMB to buy small grains neither could they rely that individuals in their area could buy these crops leaving out the more marketable maize. This limited formal marketing opportunities for the crops except for sorghum. Farmers expect spreading production and post-harvest costs on the market price, but the demand for small grains is very low in Zimbabwe.

\section{LABOUR}

Scoones (1998) listed labour in both cultivation and processing, poor technology, research emphasis given to maize and little to finger and non-production of new technologies like row planting. Rukuni, (1994) listed lack of improved varieties and credit, weeds, pests \& diseases. Maunder, (2006) argued that in Tanzania, poor cultural practices, lack of improved varieties, diseases and pests, limited uses, unpredictable markets and limited research hamper small grains. Carney (1999) listed lack of good varieties, weeds, lodging, disease, and moisture stress in dry areas. Kenya listed low research priority, limited uses, difficulty in management, lack of improved varieties, poor crop husbandry, competition from other crops with better economic returns, and lack of commercial food products (Chambers, 1992).

In Sinansengwe about 95\% respondents pointed to the labour intensiveness it has. According to an Officer at Arex Binga:

"the production of finger millet require so much labour making several people find it difficult to produce it"

In Sinansengwe many people have concurred to the fact that weeding is the most challenging aspect that requires people with advanced skills as most of the weeds look exactly like finger millet. In so doing involving someone who has limited knowledge and who fails to see the difference between finger millet and weeds will yield disappointing results. In Sinansengwe women were the major ones who were complaining about the labour intensive that finger millet has. Many of them were even pointing out that even though it can enhance food security the labour is too much hence opting to just planting it on a small piece of land. They mentioned that the crop has small seeds that prove to be laborious especially during harvesting time. Because the seeds are small, it takes skill and much effort to mill finger millet, especially by hand. Hammer mills have to be fitted with very fine screens and run at high speed, but the National Research Council, 1996, reported the development of a special mill for millet.

A respondent noted that;

'zvinotoda vanoziva uye vagara vachiirima kuti vakwanise kuziva kuti aya ndiwo mashawi iyi ndiyo mhunga. Kana tiri isu zvedu tinonzwa nekutema zviyo tichiti ndiro sora'

(finger millet growing requires those individuals with the trained eye who are able to distinguish the real millet from weeds).

Subsequently weeding is a problem making cultivation of the crop labour intensive. The difficulty in weeding is complicated by wild relatives of the crop (e.g. Eleusine indica) that look like finger millet at the time of weeding. The problem of seed size carries over into processing (Carney, 1999).

Blast caused by the fungus Pyricularia grisea (a close relative of rice blast) is the most serious disease of finger millet (Mallet, 2001). The crop has few pests, but shoot fly and stem borers, which can be controlled by insecticides. Birds are also a pest, especially, the notorious Quelea birds and other small grain feeding birds. 
The research in Sinansengwe has revealed that new sorghum and millet varieties can reduce the probability of zero yields. Thus, they can make a significant contribution to household food security in drought years (Wilhite, 2005). There has been considerable measures taken by the Government of Zimbabwe to improve the competitiveness of the small grains. New varieties and small grain processing technologies have been introduced.

Although improved sorghum and millet varieties grown in semi-arid regions, have shown potential to compete with maize in terms of productivity, the study showed that the adoption of these varieties has resulted in a decrease in land area allocation to small grains. This tends to suggest that, lacking a well-developed outlet for excess small grain outside the communal areas, high yielding improved small grains reduce the area required to achieve minimum subsistence grain requirements freeing extra land for cash crops such as maize.

All these factors highlight that if fully produced small grains can boost food security in rural households of Sinansengwe. Although there are challenges being faced being faced for instance the danger of birds and their poor taste compared to maize, these cops if fully produced can enhance food security.

\section{POOR SEED DELIVERY SYSTEMS}

While improved varieties of seeds have been released by Non-Governmental Organization, the main challenge is that the seed of these small grains is not readily available from the various seed producers. Except in South Africa, seed companies that were tasked to be conduits of government to release varieties have failed to deliver, citing low demand and the high cost of distributing the seed in far flung. This has led to the low adoption of these varieties. This is common in Zimbabwe as several farmers whether they want or do not want to promote small grain production are affected by the limited seeds of the grains. This is typical in Sinansengwe where Christian Care tries to hand out the seeds to the farmers but only in limited numbers. Be that as it may this determines the yields to be produced. In such a case many end up resorting to cultivating maize whose seeds would be readily available in markets across the country.

If small grains are to be produced, NGOs need to move beyond foundation seed and deliver seed to farmers. Generally programmes have embarked on on-farm seed production as a way of getting the seed to farmers. This has led to positive response by the farmers in the region and in the country. The need to train smallholder farmers has been encouraged as a way of ensuring that good standards are adhered to in seed production. The private sector's interest in these crops is not sufficiently high to warrant investment in openpollinated varieties but hybrids. Evidence has shown that hybrid varieties are popular to farmers however the poor farmers have been affected as they do not have the financial resources to purchase the seeds.

\section{POOR POLICY FRAMEWORK}

In that regard Rohrbach (2007) pointed out that governments need to come up with policies that favor the development of competitive intra rural markets if smallholder farmers are to be encouraged to grow sorghum and millet. This is mainly because the development of rural markets for small grains like sorghum and millet would help in providing interest for rural farmers to grow these crops. This is because they will now be growing them for both subsistence household food security as well as cash crops to meet other financial demands. Notably the government is the link that is needed small grain production is to be highly implemented. The government should assist the farmers in semi-arid areas like Binga by giving seeds particularly to those who lack the financial access to these seeds.

The Zimbabwean government has in many cases and at many occasions failed the rural people. It appears to be largely ignorant to the needs of the rural people. Development of the rural people is difficult to evidence without the involvement of the government, (Rukuni, 1994:8). The problem that the Zimbabwean government has is that it has since assumed that it is the role of NGOs to provide rural development. In so doing the government has 
remained relaxed and has left rural development largely in the hands of NGOs yet NGOs should only play a complementary role.

The field of small grain production has become of interest in recent years and this research has added emphasis on the need to incorporate small grains as a way that can promote food security. Food security is a global concern that calls for attention from development practitioners. What makes it worrisome is that agriculture which is the backbone to the survival of most people in most developing countries has been undermined by drought especially in drought prone areas. Countries that depend on agriculture have largely been affected by food insecurity recently as rainfall patterns have become erratic. The agro base of these countries has been greatly affected which in turn has affected food production. Erratic rainfall patterns due to changing climatic conditions have seriously affected weather patterns and have led to weather variability. Zimbabwe is not exempted from such issues. Zimbabwe's dependence on rain-fed agriculture especially for the rural poor people in semi-arid areas calls for concern. Sinansengwe the case that was used in this research is a semi-arid area where maize production has dismally failed. This is due to erratic rainfall patterns that have befallen the area in recent years leading to water scarcity and reducing maize yields which are depended on rainfall. The frequent occurrences of drought in the area have contributed to food insecurity leaving the ordinary people vulnerable and depending on food aid.

Small grains have been noted by experts to be better performers in drought-prone areas and are considered to have better nutritional value than maize, which is viewed as an unsuitable crop in these agricultural regions. The research has shown that small grain production is the response needed to address the effects of food security in Sinansengwe. In a country where agriculture is the dominant source of livelihood, responding to climate change should come as a necessity and as the way forward. One way that can promote food security is small grain production. Small grain production has become rampant in dry areas with promise of enhancing food security if planted on a larger scale.

Small grains have the potential to enhance household food security in the phase of climate change. This is because they are better adopted to these environments compared to maize. However, this is regardless of the challenges that they offer to the farmers in producing them. In Zimbabwe, it has been noted that small grains have received little government support to promote their production in semi-arid regions compared to maize. Though this may be, lessons of improving household food security through increased small grains production can be drawn. It has been revealed that policies promoting small grains production should be viewed beyond just enhancing household food security. Rather other benefits that accrue to the macro economy at large should also be in cooperated.

\section{PROSPECTS ON SMALL PRODUCTION IN ZIMBABWE}

Small grain production. Be as it may the cultivation of small grains is likely to continue and to increase in the near future. As much as farmers find small grain production unfavorable they will be forced to cultivate it if they want to survive. To be noted is that NGOs are likely to find it difficult to continue providing food if the people are ignorant about farming it themselves. Hand outs are supposed to be there during initial stages, however this should not be a permanent thing as it will make it seem as if the farmers will be always given food hand outs of millet if maize fails to reach expected yields at any given year. In such a case the farmers will have to realize the benefits that small grains pose to them and how their food security is increased by farming small grains. Such a realization will make them willingly adopt small grains and leave maize production which is no longer conducive in semi-arid area. In the Siansengwe area small grain production has shown positive results with many households realizing the importance of farming this crop. This response is likely to pass on to other households in the nearby areas and people will realize that it is only through small grains that their households can be secure.

Climate change. As previously mentioned small grains come as a response to climate change which has negatively impacted crop production like maize. Climate change has 
affected the semi-arid areas of Zimbabwe worsening drought occurrences in these regions which is resulting in low agricultural yields heightening food insecurity. Although climate change is a global threat, populations in developing countries, particularly in rural areas, are at greater risk because of the more limited means available for adaptation and mitigation. Climate change has increased the dependency of developing countries on food imports worsening food insecurity in sub-Saharan.

Semi-arid areas have grossly been affected, in particular, Siansengwe, where maize production has become a risk crop. In Zimbabwe, the response to this crisis has been the wide scale relief distribution of food aid and direct agricultural input assistance without an exit strategy for sustaining some of the new technologies promoted within the context of relief aid (DFID, 2009). This has led to dependence syndrome among the rural people to the donors and the government which has led to the continuation of food insecurity as most of the solution prove to be non-viable. Small grains is a viable solution that can be a lasting solution to food insecurity mainly because of their adaptation capabilities to hot dry humid areas that are being affected by climate change. As previously mentions small grains like sorghum and finger millet can withstand high temperatures and can thrive in drought prone areas like Siansengwe. They therefore are the present and future solution to food insecurity in semiarid areas.

The zimbabwean government. The government of Zimbabwe views access to land by the majority as the basis for eradicating poverty and increasing food security. Food availability has, however, declined over the last decade. There seems to be little incentive for farmers to produce beyond their subsistence needs, given the lack of alternative marketing channels and the presence of price controls with static procurement prices in an environment of hyperinflation. Food availability has also been worsened by issues like climate change which is opening more spaces of the vulnerability. Considering the prevalence of food insecurity the Zimbabwean government in conjunction with NGOs has been involved in small grain production as a means of enhancing food security.

NGOs in Zimbabwe need to be complemented by the government if development is to prevail. Despite the deterioration in the food security situation in Zimbabwe the government of Zimbabwe has been issuing agricultural input aid (seed and fertilizer) to communal and resettled farmers as an agricultural recovery strategy (Dube, 2008). Nonetheless, Maunder (2006) suggest that not much benefit has been achieved from the government's subsidized input scheme especially in the semi-arid regions because input type and variety that was being issued did not tally with the agro-ecological location of the farmer. Issuing inputs to boost production of smallholder farmers, equipping them with improved crop management practices can assist in improving Zimbabwe's food security situation (FAO, 2000).

In addition, FAO (2008) further supports the same notion that inputs need to suit farmer agro ecological region for better returns to be realized if Zimbabwe is to address its food security situation through increased agricultural production. FAO (2000) goes on to suggest that inputs of sorghum and millets should be distributed to low rainfall areas while inputs of maize should be distributed to high rainfall areas. In addition, Rohrbach (2007) revealed that there has not been much diversification from maize as the dominant source of food in Zimbabwe. Even in drier areas where small grains can be produced economically and sustainably, maize is the mainstay of household food security (Rukuni et al., 2006). Hence, production of sorghum and millet is seen as another crop diversification strategy that can alleviate food security in Zimbabwe's semi-arid regions (Rukuni et al., 2006). It is the Zimbabwean government which should highly promote crop diversification with small grain production as the compulsory grain to be grown by all farmers in semi-arid areas like in Siansengwe.

Economic growth. According to World Bank, (2008), most livelihoods approaches imply that food security is the only desired outcome of household livelihood strategies without also taking into consideration issues such as having increased income, stronger 'voice', reduced vulnerability or sustainable use of the natural resources base (Dercon, 2002). Food production in Zimbabwe, previously the breadbasket of Southern African, has remained below subsistence levels since 2000, contributing to an economy-wide adverse effect. The 
agricultural sector has for many years suffered neglect that has resulted in decreased agricultural productivity which have strongly led to economic decline. Decreased production in this sector has also been affected by the government's land reform program. Crumbling irrigation systems and infrastructure in general has reduced agricultural production, resulting in widespread shortages of goods and services, high unemployment levels and declining living standards (Juana, 2012).

Concerning that agriculture forms the backbone of Zimbabwe's economy climate change has also been a contributory factor in the decline of economic growth in the country. Maize production has declined and the country is now an importer of maize. Furthermore climate change has increased semi-arid areas in the country reducing maize production areas. Small grains now come into play as a way that can help in boosting up the economy of Zimbabwe again. There is the need to realize the importance of these crops in enhancing food security not only on a national level but also on a commercial level. FAO (2000) explain that commercial processing of sorghum and millet into value added products in developing countries has the potential to stimulate economic development in these countries.

Therefore, policies that support increased production of sorghum and millet should be viewed in a holistic approach regarding contributions they can make to the macro economy and not only as a means of increasing food security to those in semi-arid areas. In Zimbabwe, it has been deduced that the industrial and commercial use of sorghum and all small grains in general are very limited (Wilhite et al., 2000). That being the case, Rohrbach, 2007:34) mentions that gains to the economy from increased industrial use of small grains will have ripple effects besides just improving rural food security. These include but are not limited to reducing the need for drought relief, lowering the level of subsidies underlying grain markets, and, at least in the short run, stemming migration from rural to urban areas. So all in all it can be seen that the prospects of small grain production are much higher compared to its demerits. The only demerits of these crops in on its plantation process which is outweighed by the benefits that they bring in the long run after the harvest period.

\section{REFERENCES}

1. Amnesty International. (2004). Zimbabwe, Violations of the Right to Food. Press Release 15 October, 2004.

2. Bang, S.K. \& Sitango, K. (2003). Indigenous Drought Coping Strategies and Risk Management against EL Nino in Papua New Guinea: CGPRT centre working paper No. 74.

3. Barrett, C. B. \& Maxwell, D.G., (2005). Food Aid After Fifty Years: Recasting Its Role. Routeledge, New York.

4. Carney, D. \& Ashley C. (1999). The Sustainable Livelihood Approach to Poverty Reduction. Canada: SIDA

5. Chambers, Robert and Gordon Conway, (1992). Sustainable Rural Livelihoods: Practical concepts for the 21st Century. IDS Discussion Paper 296, IDS, Brighton, UK.

6. Dercon, S. (2002). 'Income Risk, Coping Strategies and Safety Nets', World Institute of Development economics Research, Discussion paper NO 2002/22, United Nations University.

7. Dube, C. (2008). The impact of Zimbabwe's drought policy on Sontala Rural Community in Matabeleland South Province. MSc Thesis, Department of geology, Geography and environmental studies; Stellenbosch University.

8. Food and agriculture organization FAO. (2000). Socio-economic impact of smallholder irrigation development in Zimbabwe.

9. Food and agriculture organization FAO. (2010). Crop and Livestock Assessment. 2nd round. (Unpublished Doc.)

10. Juana, J. S., \& Ignowski E, 2012, Two Essays on Food Security in Zimbabwe, University of Illinois at Urbana-Champaign, 2012 
11. Mallet, M. \& Plessis, P. (2001). A summary of current Knowledge about Pearl millet PostHarvest Issues in Namibia: Ministry of Agriculture, Water and Rural Development. Windhoek, Namibia.

12. Maunder, N. \& Tembo, G. (2006). The Impact of Food Aid on Grain Markets in Southern Africa: Implications for Tackling Chronic Vulnerability. New York: Cornell University Press.

13. Ndlovu B, (2011), Drought copying strategies at Mutasa district in Zimbabwe, University of Free State.

14. Riches, G. (ed.). (1997). First World Hunger: Food Security and Welfare Politics. New York, N.Y.: St. Martin's Press.

15. Rohrbach, D \& Kiriwaggulu. J. (2007). Journal on Commercialization Prospects for Sorghum and Pearl Millet in Tanzania, 3(1):1-24.

16. Rukuni. M \& Eicher, C. K., (1994). Zimbabwe's Agricultural Revolution. University of Zimbabwe Publications Office. Harare, Zimbabwe.

17. Scoones, lan. (1998), Sustainable Rural Livelihoods: A framework for analysis. IDS, Working Paper 72, IDS, Brighton, UK.

18. Wilhite, D.A. (1991). Drought planning: A process for State government. Water Resources Bulletin. 27 (1): 29-38.

19. Wilhite, D.A., Hays, M.J., Knutson, C. \& Smith, K.H. (2000). Planning for drought: Moving from crisis to risk management. Journal of the American water Resources association 36: 697-710.

20. Wilhite, D.A., Hays, M.J. \& Knutson, C. L. (2005). Drought preparedness planning: building Institutional capacity.

21. World Bank (2008). World Development Report 2008: Agriculture for Development. Washington, DC.

22. ZimVAC. (2009). Zimbabwe Vulnerability Assessment Committee (ZimVAC) Interim Rural Food Security Assessment. Co-ordinated by the Scientific Industrial Research and Development (SIRDIC) \& Food and Nutrition Council (FNC), Harare, Zimbabwe. 